Keywords: circulating tumour cells; metastatic breast cancer; immunohistochemical subtypes; CellSearch system; prognostic significance

\title{
Detection and prognostic significance of circulating tumour cells in patients with metastatic breast cancer according to immunohistochemical subtypes
}

D J E Peeters ${ }^{\star}, 1,2,4$, P-J van Dam ${ }^{1}$, G G M Van den Eynden ${ }^{1}$, A Rutten ${ }^{1}$, H Wuyts ${ }^{1}$, L Pouillon ${ }^{1}$, M Peeters ${ }^{2}$, P Pauwels ${ }^{3}$, S J Van Laere ${ }^{1}$, P A van Dam ${ }^{1,2}$, P B Vermeulen ${ }^{1}$ and L Y Dirix ${ }^{1}$

${ }^{1}$ Translational Cancer Research Unit, Oncology Centre GZA Hospitals Sint-Augustinus, Oosterveldlaan 24, B-2610 Antwerp, Belgium; '2Department of Oncology, University of Antwerp and Antwerp University Hospital, Universiteitsplein 1, B-2610 Antwerp, Belgium and ${ }^{3}$ Department of Pathology, University of Antwerp and Antwerp University Hospital, Universiteitsplein 1, B-2610 Antwerp, Belgium

Background: The enumeration of circulating tumour cells (CTCs) with the EpCAM-based CellSearch system has prognostic significance in patients with metastatic breast cancer (MBC). The aim of this study was to explore potential differences in the detection and prognostic significance of CTCs in MBC according to immunohistochemical subtypes of breast cancer.

Methods: CellSearch CTC counts were obtained from 154 MBC patients before first-line systemic treatment between November 2007 and August 2012. Patients were categorised in five subgroups according to immunohistochemical surrogate definitions of intrinsic subtypes in breast cancer based on hormone receptor status, HER2/neu status and histological grade. Differences in progression-free (PFS) and overall survival (OS) were assessed relative to the cut-off value of $\geqslant 5$ CTCs per $7.5 \mathrm{ml}$ blood.

Results: No significant differences were observed in the absolute CTC counts $(P=0.120)$ or in CTC positivity rates according to $\geqslant 1$ and $\geqslant 5$ CTCs per $7.5 \mathrm{ml}$ blood detection thresholds $(P=0.165$ and $P=0.651$, respectively) between immunohistochemical subtypes. However, very high CTC counts, defined as $\geqslant 80$ CTCs per $7.5 \mathrm{ml}$, were observed more frequently in patients with Luminal $A$ and triple negative $(T N)$ breast cancer $(P=0.024)$. In the total study population, the presence of $\geqslant 5 C T C s$ was the single most significant prognostic factor for both PFS and OS in multivariate analysis $(P<0.001)$. A more limited prognostic impact, not reaching statistical significance, was observed in patients with HER2-positive disease as opposed to patients with Luminal A, Luminal B-HER2-negative and TN disease.

Conclusion: The detection of EpCAM + CTCs was not clearly associated with any of the immunohistochemical subtypes of breast cancer in patients with MBC before first-line treatment. Potentially clinically relevant differences were however observed at very high CTC counts. Furthermore, our data suggest a lower prognostic significance of CTC evaluation in HER2-positive patients with $\mathrm{MBC}$.

The enumeration of circulating tumour cells (CTCs) has repeatedly been shown to be a strong prognostic factor with respect to progression-free (PFS) and overall (OS) survival in patients with metastatic breast cancer (MBC; Cristofanilli et al, 2004; Pierga et al, 2012; Zhang et al, 2012). The CellSearch system (Veridex, Raritan, NJ, USA) is currently the only platform that has acquired FDA

*Correspondence: Dr DJE Peeters; E-mail: dieter.peeters@gza.be

${ }^{4}$ DJEP is a research assistant of the Fund for Scientific Research Flanders.

Received 21 August 2013; revised 2 September 2013; accepted 1 November 2013; published online 24 December 2013

(c) 2014 Cancer Research UK. All rights reserved 0007-0920/14 
clearance (Kahan, 2004) for clinical use of CTC enumeration and has found the most widespread implementation in clinical and translational research units. With this system, CTCs are isolated from whole blood based on the immunomagnetic labelling of EpCAM, a transmembrane protein expressed in the majority of human epithelial cancers, and the subsequent (immuno)fluorescent labelling of cytokeratins 8/18/19, CD45 and the cell nucleus using DAPI to allow correct CTC identification among the remaining co-enriched white blood cells.

Human breast cancer is a grouping of many different disease entities. This became obvious during initial genome-wide geneexpression profiling studies and has led to the adoption of a molecular taxonomy encompassing at least four main molecular subtypes (the Luminal A and B, basal-like and HER2-enriched subtype; Perou et al, 2000). The clinical relevance of this taxonomy has been investigated and confirmed by many research groups (Sorlie et al, 2003; Sotiriou et al, 2003; Van Laere et al, 2007). The robustness of this taxonomy was recently reconfirmed in a large study combining profiling data of DNA copy number arrays, DNA methylation, exome sequencing, messenger RNA arrays, microRNA sequencing and reverse-phase protein arrays of primary breast cancers from 825 patients (The Cancer Genome Atlas Network, 2012). As molecular profiling data are not routinely available in a clinical setting, the 12th St Gallen International Breast Cancer Conference (2011) Expert Panel has introduced more pragmatic surrogate definitions to approximate these intrinsic subtypes using immunohistochemical staining results of oestrogen (ER) and progesterone (PR) receptors, the detection of overexpression and/or amplification of the HER2/neu oncogene, and Ki-67-labelling index and/or histological grade (Goldhirsch et al, 2011).

Questions to what extent this molecular heterogeneity affects the detection and prognostic significance of CTCs as assessed with the CellSearch system have not been fully elucidated. Experiments with cell line models have shown that, particularly, cell lines with a normal-like gene expression profile - all of which being used had the triple-negative (TN) phenotype - were less efficiently recovered by the system (Sieuwerts et al, 2009). Furthermore, it has been demonstrated that EpCAM is variably expressed between intrinsic subtypes at the level of the primary tumour with the highest expression observed in HER2 + and the lowest expression observed in Luminal A tumours (Soysal et al, 2013). In addition, several retrospective studies have been reported in which potential differences in the detection and prognostic significance of CTCs according to immunohistochemically defined subtypes of breast cancer were explored (Giordano et al, 2012; Munzone et al, 2012; Wallwiener et al, 2012). However, these studies included a majority of patients that were already pretreated for metastatic disease, potentially confounding the normal biological behaviour of CTCs. Here we report on the detection and prognostic significance of CTCs according to immunohistochemically defined subtypes of breast cancer in a large, single-centre and clinically uniform patient cohort of 154 patients with MBC before the start of first-line treatment. The results of this study are reported in compliance with the REMARK guidelines, if applicable (McShane et al, 2005).

\section{MATERIALS AND METHODS}

Patients and sample collection. We retrospectively searched our institutional database for patients with MBC who had undergone CTC evaluation before first-line treatment for metastatic disease between November 2007 and August 2012. All patients were recruited at the Oncology Centre of GZA Hospitals SintAugustinus (Antwerp, Belgium). Since the introduction of the CellSearch system in our research unit in November 2007, patients with breast cancer presenting with a new diagnosis of metastatic disease are systematically proposed to participate in a translational research programme aiming at the quantification and molecular characterisation of CTCs. Clinical, histopathological, treatment and survival data of all participating patients are collected from inhospital electronic medical records and entered in a database, which is regularly updated. Treatment re-evaluations are being performed every 6-8 weeks as a standard of care. Results on CTC counts were not shared with the treating physician or the patient at the time of treatment evaluation. Follow-up (FU) blood samples under treatment were not systematically collected, but taken into account for this study whenever available. All patients gave written informed consent for CTC assessment and collection of clinicopathological and survival data according to a protocol approved by the ethical review boards of GZA Hospitals Sint-Augustinus (Antwerp, Belgium) and the University of Antwerp (file number UA A11-18).

Definition of immunohistochemical subtypes. Patients were categorised into five subgroups based on the St Gallen surrogate definitions of intrinsic breast cancer subtypes (Goldhirsch et al, 2011), taking into account hormonal receptor status (ER/PR), HER2/neu status (hereafter referred to as HER2) and BloomRichardson (BR) histological grade. Hormonal receptor status was considered positive when an Allred score $\geqslant 3$ was reported. HER2 status was considered positive when a positive FISH result defined as a ratio of HER2 over CEP17 > 2.2 - was documented or when in the absence of a FISH result an immunohistochemal score of $3+$ according to the 2007 ASCO-CAP guidelines for immunohistochemical testing of HER2 was reported. Patients with BR grade I-II, ER- and/or PR-positive and HER2-negative tumours were classified as 'Luminal A'. Patients with BR grade III, ER- and/or PR-positive and HER2-negative tumours were classified as 'Luminal B-HER2 negative'. Patients with ER- and/ or PR-positive and HER2-positive tumours of any grade were classified as 'Luminal B-HER2 positive'. Patients with ER/PR negative and HER2 positive of any grade were classified as 'HER2 positive (non-luminal)' and patients with tumours that were negative for both ER/PR and HER2 regardless of BR grade were classified as 'TN'. Patients with bilateral breast tumours of different immunohistochemical phenotypes that could not be classified unambiguously in one subgroup were entered in the database as having missing data for the discordant variable(s) and the subgroup variable.

CTC enumeration. CTC enumeration was performed with the FDA approved CellSearch system (Veridex, LLC) using the IVD CellSearch CTC kit according to manufacturer's instructions as described before (Van Der Auwera et al, 2010). Positive CellSearch CTC control samples were run in all batches containing patient samples and were within the predefined limits in all experiments. Image galleries of each CTC sample were analysed by two experienced readers. Questionable interpretations were evaluated again until consensus was reached. Results of CTC enumeration are always reported as the number of cells per $7.5 \mathrm{ml}$ of blood.

Statistical analysis. Data were analysed using the statistical software package SPSS Statistics version 20 (IBM, Armonk, NY, USA). Differences in continuous CTC counts and categorical variables were tested using non-parametric Kruskal-Wallis and Mann-Whitney $U$-tests. Associations of CTC positivity rates according to $\geqslant 1, \geqslant 5$ and $\geqslant 80$ CTCs per $7.5 \mathrm{ml}$ blood cut-off points and clinicopathological variables were tested with Pearson's $\chi^{2}$-test. A multivariate logistic generalised linear regression model was used to estimate the association of relevant clinicopathological variables with CTC positivity rates of $\geqslant 5$ CTCs per $7.5 \mathrm{ml}$ blood. The prognostic value of CTC evaluation was assessed relative to the previously determined prognostic cut-off value of $<5$ (favourable 
Table 1. Patient characteristics and associations with CTC counts

No. of patients with $\geqslant 5$ СТC

\begin{tabular}{|c|c|c|c|c|c|c|}
\hline \multirow[b]{2}{*}{ Variable } & \multirow[b]{2}{*}{ All patients } & \multirow[b]{2}{*}{$\begin{array}{c}\text { No. of patients with } \\
\geqslant 1 \text { CTC }\end{array}$} & \multirow[b]{2}{*}{ Univariate } & \multicolumn{2}{|c|}{$\begin{array}{c}\text { Multivariate logistic GLM } \\
\text { model }\end{array}$} & \multirow[b]{2}{*}{$\begin{aligned} \text { No. of patients } \\
\geqslant 80 \text { CTC }\end{aligned}$} \\
\hline & & & & $\begin{array}{l}\text { Effect estimator } \\
(95 \% \mathrm{Cl})\end{array}$ & $P$-value & \\
\hline & $154(100 \%)$ & $105(68 \%)$ & 70 (46\%) & - & - & $20(13.0 \%)$ \\
\hline \multicolumn{7}{|l|}{ Age } \\
\hline $\begin{array}{l}<\text { Median } \\
\geqslant \text { Median }\end{array}$ & $\begin{array}{l}77(50 \%) \\
77(50 \%)\end{array}$ & $\begin{array}{c}49(64 \%) \\
56(73 \%) \\
P=0.226\end{array}$ & $\begin{array}{l}30(39 \%) \\
40(52 \%) \\
P=0.106\end{array}$ & $\begin{array}{c}1 \\
1.8(0.9-3.9)\end{array}$ & $\overline{0} \cdot 122$ & $\begin{array}{c}9(12 \%) \\
11(14 \%) \\
P=0.632\end{array}$ \\
\hline
\end{tabular}

Molecular subgroup

\begin{tabular}{|c|c|c|c|c|c|c|}
\hline Luminal A & $56(36 \%)$ & 39 (70\%) & 29 (52\%) & 1 & - & $11(20 \%)$ \\
\hline Luminal B-HER2-negative & 29 (19\%) & $16(55 \%)$ & $10(35 \%)$ & $0.7(0.2-2.2)$ & 0.593 & $2(7 \%)$ \\
\hline Luminal B-HER2-positive & 35 (23\%) & $21(60 \%)$ & $16(46 \%)$ & $2.1(0.8-6.1)$ & 0.154 & $1(3 \%)$ \\
\hline HER2-positive (non-luminal) & $14(9 \%)$ & $12(86 \%)$ & 7 (50\%) & $1.9(0.5-7.6)$ & 0.335 & $1(7 \%)$ \\
\hline Not classified (missing data) & $4(3 \%)$ & $P=\overline{0.165}$ & $P=\overline{0.651}$ & - & - & $P=\overline{0.024}$ \\
\hline
\end{tabular}

Histological subtype

Invasive ductal carcinoma ${ }^{a}$

Invasive lobular carcinomab

Missing data

$128(83 \%)$

$25(16 \%)$

$83(65 \%)$

$21(84 \%)$

$1(1 \%)$

$P=0.060$

48 (38\%)

21 (84\%)

-

$P<0.001$

\begin{tabular}{c|c|c}
1 & - & $12(9 \%)$ \\
$12.2(3.2-45.0)$ & $<0.001$ & $8(32 \%)$ \\
- & - & - \\
& & $\boldsymbol{P}=\mathbf{0 . 0 0 2}$
\end{tabular}

Number of organs involved

\begin{tabular}{|c|c|c|c|c|c|c|}
\hline$<3$ & 89 (58\%) & $56(63 \%)$ & 33 (37\%) & 1 & - & $9(10 \%)$ \\
\hline$\geqslant 3$ & 65 (42\%) & $\begin{array}{c}49(75 \%) \\
P=0.101\end{array}$ & $\begin{array}{c}37(57 \%) \\
\boldsymbol{P}=0.015\end{array}$ & $1.7(0.8-3.8)$ & 0.177 & $\begin{array}{l}11(17 \%) \\
P=0.214\end{array}$ \\
\hline
\end{tabular}

Bone metastasis

\begin{tabular}{|c|c|c|c|c|c|c|}
\hline $\begin{array}{l}\text { Absent } \\
\text { Present } \\
\text { Missing data }\end{array}$ & $\begin{array}{c}45(29 \%) \\
108 \text { (70\%) } \\
1(1 \%)\end{array}$ & $\begin{array}{c}21(47 \%) \\
84(78 \%) \\
- \\
P<0.001\end{array}$ & $\begin{array}{c}9(20 \%) \\
61(57 \%) \\
- \\
P<0.001\end{array}$ & $\begin{array}{c}1 \\
5.5(2.3-13.6) \\
-\end{array}$ & $\begin{array}{c}<0.001 \\
-\end{array}$ & $\begin{array}{c}4(9 \%) \\
16(15 \%) \\
- \\
P=0.322\end{array}$ \\
\hline \multicolumn{7}{|c|}{ Visceral metastasis } \\
\hline $\begin{array}{l}\text { Absent } \\
\text { Present }\end{array}$ & $\begin{array}{l}67(44 \%) \\
87(56 \%)\end{array}$ & $\begin{array}{c}45(67 \%) \\
60(69 \%) \\
P=0.812\end{array}$ & $\begin{array}{l}30(45 \%) \\
40(46 \%) \\
P=0.882\end{array}$ & $\begin{array}{c}1 \\
1.5(0.6-3.5)\end{array}$ & $\overline{0.358}$ & $\begin{array}{c}8(12 \%) \\
12(14 \%) \\
P=0.735\end{array}$ \\
\hline
\end{tabular}

Abbreviations: $\mathrm{Cl}=$ confidence interval; $\mathrm{CTC}=$ circulating tumour cells; $\mathrm{GLM}=$ generalised linear regression model. Bold values indicate significant $P$-values $(P<0.05)$.

ancluding one patient with invasive medullar carcinoma and one patient with mixed invasive ductal and apocrine carcinoma.

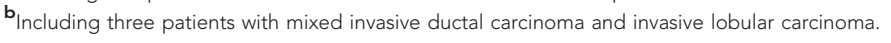

prognosis) $v s \geqslant 5$ (unfavourable prognosis) CTCs per $7.5 \mathrm{ml}$ blood (Cristofanilli et al, 2004). Endpoints were PFS and OS. PFS was defined as the time from baseline CTC evaluation to clinical or radiological progression, or death from any cause, whichever came first. Overall survival was defined as the time from baseline CTC evaluation to death from any cause. Patients who had not shown disease progression or were still alive at the date of last FU were censored for PFS and/or OS, respectively. Survival data were last updated on 28 February 2013, after which date the data were locked. Survival curves were calculated with Kaplan-Meier estimates and compared using the log-rank test. Follow-up times were calculated from the reverse Kaplan-Meier estimator according to Schemper and Smith (1996). Cox's proportional hazard regression models were used for univariate and multivariate (using the conditional backward stepwise elimination procedure with a 0.05 threshold for entry in the model and 0.10 threshold for exclusion) analysis of prognostic impact of relevant variables. All univariate analyses were run on complete cases only. For multivariate models, missing values (occurring in $5-15 \%$ of cases depending on the variables included in the tested models) were imputed using the multiple imputation procedure, using logistic regression as imputation method for categorical variables generating five imputed data sets for which results were pooled. For all statistical tests, $P$-values were calculated two-sided and considered statistically significant when $<0.05$. Statistical trends were assumed for $P$-values between 0.05 and 0.10 . 


\section{RESULTS}

Patient population. In total, 154 patients with $\mathrm{MBC}$, who had undergone CTC evaluation before the start of first-line treatment, were identified. A REMARK diagram schematically illustrating the patient selection for this study is shown in Supplementary Figure 1. Median age of the study population was 62.1 years (32.9-90.8 years range). Five or more CTCs were detected in 70 (45.5\%) patients. Fifty-six (36.4\%) patients were classified as Luminal A, 29 (18.8\%) patients as Luminal B-HER2 negative, 35 (22.7\%) patients as Luminal B-HER2 positive, 14 (9.1\%) patients as HER2 positive

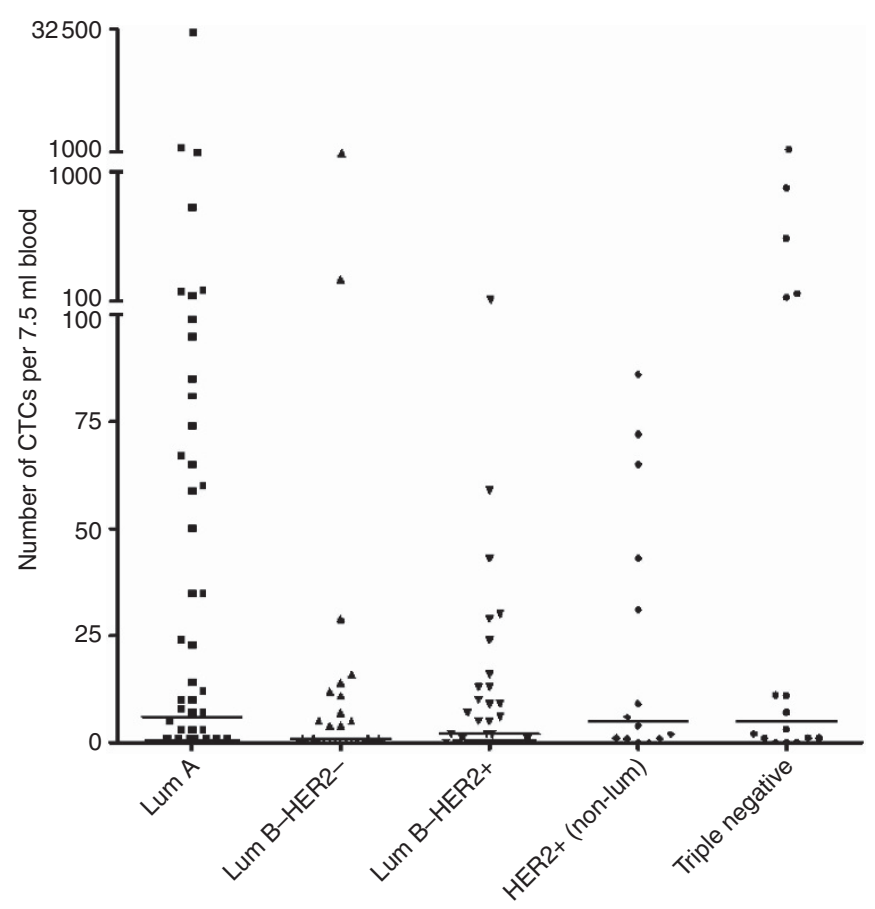

Figure 1. Number of CTCs per $7.5 \mathrm{ml}$ blood according to immunohistochemical subtype. (non-luminal) and $16(10.4 \%)$ patients as TN. Four (2.6\%) patients could not be classified due to missing data $(n=3)$ or a history of bilateral breast tumours of different immunohistochemical phenotype $(n=1)$. Thirty-six $(23.4 \%)$ patients had metastatic disease limited to the bone. A FU CTC count after the initiation of treatment was available for 75 of 154 (48.7\%) patients. Other patient characteristics are summarised in Table 1.

Administered treatments. Administered first-line treatments were as follows: $79(51.3 \%)$ patients were treated with cytotoxic chemotherapy, 72 (46.8\%) patients received endocrine treatment as primary therapy, 44 of 49 (89.8\%) patients with HER2-positive disease received anti-HER2 directed therapies (including trastuzumab, lapatinib, pertuzumab and TDM1) as part of their first-line treatment and $9(5.8 \%)$ patients received bevacizumab. In total, 25 patients were treated in the experimental arm of clinical studies with an investigational agent. One elderly patient with limited bone disease from a TN tumour was treated with radiotherapy and bisphosphonates alone.

Association of CTC counts and clinicopathological variables. Associations of CTC counts at different cut-off points with clinicopathological variables and immunohistochemical subtypes are summarised in Table 1. Median numbers of CTCs were 3 (range 0-32 492) in the total study population, 6 (range 0-32 492) in patients in the Luminal A subgroup, 1 (range 0-1161) in patients in the Luminal B-HER2-negative subgroup, 2 (range $0-115)$ in patients in the Luminal B-HER2-positive subgroup, $5(0-86)$ in patients in the HER2-positive (non-luminal) subgroup and $5(0-1101)$ in patients in the TN subgroup (Figure 1). No statistically significant difference was observed in the absolute number of CTCs between immunohistochemically defined subtypes $(P=0.120)$. No associations were found between any of the immunohistochemically defined subtypes and CTC detection at a $\geqslant 1$ CTC per $7.5 \mathrm{ml}$ threshold or CTC positivity rates at the $\geqslant 5$ CTCs prognostic cut-off point. However, the detection of highly elevated CTC counts above an arbitrarily chosen threshold of 80 CTCs (corresponding to $<15 \%$ of patients in the entire study population) was observed significantly more frequently in patients with Luminal A and TN primary tumour characteristics $(P=0.024)$. Significantly higher numbers of CTCs were observed in patients with lobular carcinomas (median: 35; range: 0-32 492)

Table 2. Summary of survival data for progression-free and overall survival according CTC count and immunohistochemical subtype

\begin{tabular}{|c|c|c|c|c|c|c|c|c|}
\hline \multirow[b]{2}{*}{ Subgroup } & \multirow[b]{2}{*}{$\begin{array}{c}\text { CTC } \\
<\text { or } \geqslant 5\end{array}$} & \multirow[b]{2}{*}{ All } & \multicolumn{3}{|c|}{ PFS } & \multicolumn{3}{|c|}{ os } \\
\hline & & & Events & $\begin{array}{l}\text { Median survival } \\
\text { (months) }\end{array}$ & $\begin{array}{c}\text { Log-rank } \\
\boldsymbol{P} \text {-value }\end{array}$ & Events & $\begin{array}{l}\text { Median survival } \\
\text { (months) }\end{array}$ & $\begin{array}{c}\text { Log rank } \\
P \text {-value }\end{array}$ \\
\hline \multirow[t]{2}{*}{ All } & $<5$ & 84 & 52 & $17.6(14.7-20.5)$ & $<0.001$ & 21 & NR & $<0.001$ \\
\hline & $\geqslant 5$ & 70 & 55 & $9.2(5.8-12.6)$ & & 35 & $26.3(16.7-35.9)$ & \\
\hline \multirow[t]{2}{*}{ Luminal A } & $<5$ & 27 & 17 & $18.5(15.1-21.9)$ & 0.023 & 4 & NR & 0.003 \\
\hline & $\geqslant 5$ & 29 & 22 & $9.5(4.8-14.2)$ & & 15 & $21.0(13.1-28.9)$ & \\
\hline \multirow[t]{2}{*}{ Luminal B-HER2-negative } & $<5$ & 19 & 14 & $16.6(8.7-24.5)$ & 0.051 & 6 & NR & 0.057 \\
\hline & $\geqslant 5$ & 10 & 8 & $5.0(0.1-10.0)$ & & 5 & $26.3(0.1-56.0)$ & \\
\hline \multirow[t]{2}{*}{ Luminal B-HER2-positive } & $<5$ & 19 & 10 & $17.6(10.7-24.5)$ & 0.301 & 5 & NR & 0.382 \\
\hline & $\geqslant 5$ & 16 & 12 & $11.7(9.1-14.3)$ & & 7 & $31.3(25.8-36.8)$ & \\
\hline \multirow[t]{2}{*}{ HER2-positive (non-luminal) } & $<5$ & 7 & 4 & $19.0(10.0-28.0)$ & 0.311 & 0 & NR & 0.197 \\
\hline & $\geqslant 5$ & 7 & 5 & $10.1(0.3-19.9)$ & & 1 & NR & \\
\hline \multirow[t]{2}{*}{ Triple negative } & $<5$ & 8 & 7 & $13.4(9.2-17.6)$ & 0.009 & 6 & $25.4(16.0-34.8)$ & 0.019 \\
\hline & $\geqslant 5$ & 8 & 8 & $2.1(0.7-3.5)$ & & 7 & $2.8(0.1-9.3)$ & \\
\hline
\end{tabular}


as compared with patients with ductal primary tumour histology (median: 1 ; range: $0-1161 ; P<0.001$ ), in patients with metastatic disease in 3 or more organs (median: 8; range: $0-2262$ ) as compared with patients with metastases in less than 3 organs (median: 1; range $0-32492 ; P=0.016$ ) and in patients with bone metastases (median: 7; range: 0-32 492) as compared with patients without bone metastases (median: 0 ; range: $0-886$; $P<0.001$ ).
No associations were observed between (unfavourable) CTC counts and age or the presence of visceral metastatic disease (defined here as metastases in the liver, lungs and/or brain). In multivariate analysis, the presence of metastatic disease to the bone and invasive lobular primary tumour histology were the only factors that were significantly associated with the detection of $\geqslant 5$ CTCs per $7.5 \mathrm{ml}$ blood.
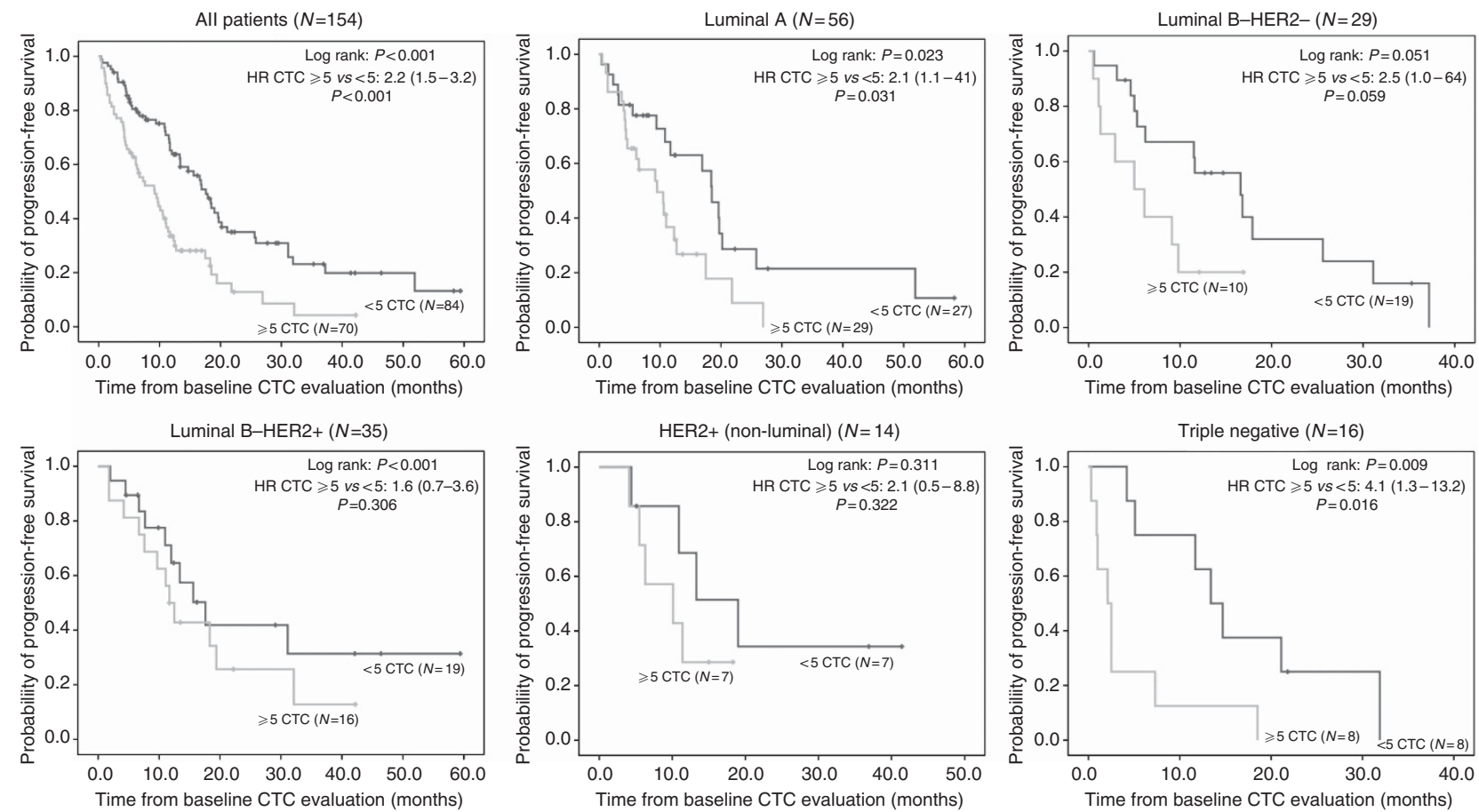

Figure 2. Kaplan-Meier curves of PFS for the entire study population and patients classified by immunohistochemical subtype relative to the $\geqslant 5$ CTCs prognostic cutoff.
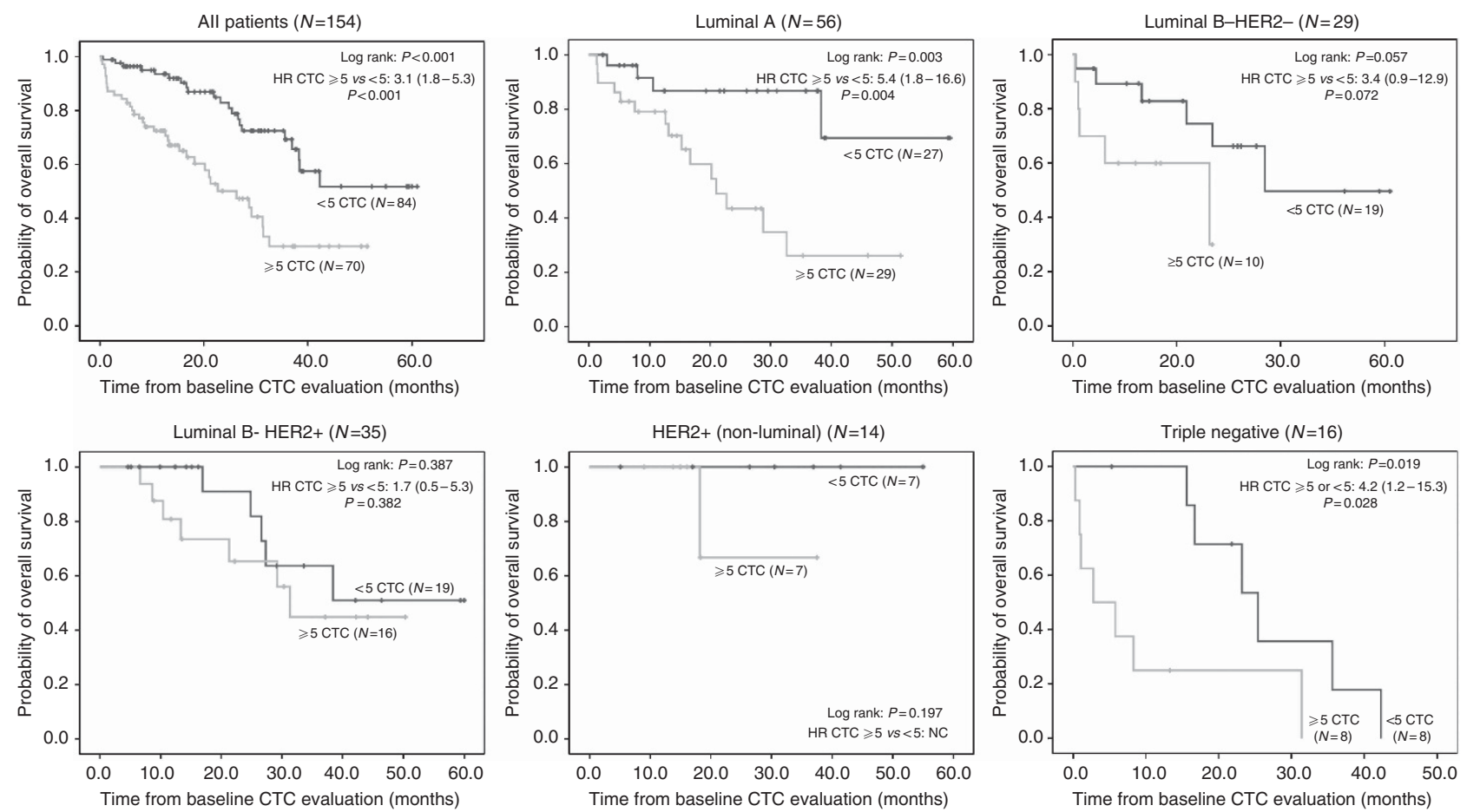

Figure 3. Kaplan-Meier curves of OS for the entire study population and patients classified by immunohistochemical subtype relative to the $\geqslant 5$ CTCs prognostic cutoff. 
Comparison of CTC prognostic value between immunohistochemical subtypes. After a median FU of 27.7 months for PFS and 29.1 months for OS, 107 patients had showed disease progression under first-line treatment and 56 patients had died. Median PFS was 12.0 (95\% CI, 10.1-13.9) months in the total study population. Median OS for all patients was 37.0 (95\% CI, 28.2-45.7) months. The presence of $\geqslant 5$ CTCs was associated with a decreased OS and PFS in the total study population and all immunohistochemical subtypes (Table 2). However, no statistical significance was reached in patients with HER2-positive disease (Table 2 and Figures 2 and 3 ) and only statistical trends of a survival benefit in the $<5$ CTCs group were observed in patients with Luminal B-HER2-negative disease. Patients with TN breast cancer had the worst prognosis, especially when having $\geqslant 5$ CTCs. Longest OS was observed in patients with HER2-positive disease regardless of CTC counts relative to the $\geqslant 5$ CTCs cut-off point.

Multivariate survival analysis. Following parameters were evaluated for prognostic impact with respect to PFS and OS in the multivariate Cox regression analysis: CTC count $(<5$ vs $\geqslant 5)$, age $(<$ median $v s \geqslant$ median $)$, immunohistochemically defined subgroup, histological subtype (ductal or lobular), the number of organs affected by metastatic disease $(<3 v s \geqslant 3)$, presence of visceral metastatic disease, presence of metastatic disease limited to the bone, time-to-metastasis $(<5 v \geqslant 5$ years from diagnosis), main treatment modality (chemotherapy or anti-hormonal treatment) and serological markers CA15.3 and LDH ( $<$ upper limit of normal (ULN) or $\geqslant U L N)$. The presence of $\geqslant 5$ CTCs was the only factor that was significantly associated with both shorter PFS

\begin{tabular}{|c|c|c|c|}
\hline \multicolumn{4}{|c|}{$\begin{array}{l}\text { Table 3. Results of multivariate Cox proportional hazare } \\
\text { analysis for progression-free and overall survival } \\
\qquad \begin{array}{l}\text { PFS }\end{array}\end{array}$} \\
\hline Variable & HR & $95 \% \mathrm{Cl}$ & $\boldsymbol{P}$-value \\
\hline $\mathrm{CTC}(\geqslant$ vs $<5)$ & 2.6 & $1.7-4.0$ & $<0.001$ \\
\hline Bone-only metastatic disease & 0.5 & $0.3-0.8$ & 0.015 \\
\hline \multicolumn{4}{|l|}{ Molecular subgroup } \\
\hline $\begin{array}{l}\text { Luminal A } \\
\text { Luminal B-HER2-negative } \\
\text { Luminal B-HER2-positive } \\
\text { HER2-positive (non-luminal) } \\
\text { Triple negative }\end{array}$ & $\begin{array}{l}1 \\
1.5 \\
0.7 \\
0.7 \\
1.8\end{array}$ & $\begin{array}{l}- \\
0.8-2.6 \\
0.4-1.1 \\
0.3-1.5 \\
1.0-3.4\end{array}$ & $\begin{array}{l}- \\
0.132 \\
0.113 \\
0.364 \\
0.071\end{array}$ \\
\hline \multirow{2}{*}{ Triple negative } & \multicolumn{3}{|c|}{ OS } \\
\hline & HR & $95 \% \mathrm{Cl}$ & $\boldsymbol{P}$-value \\
\hline $\mathrm{CTC}(\geqslant$ vs 5$)$ & 3.2 & $1.8-5.7$ & $<0.001$ \\
\hline Age $(\geqslant v s<$ median $)$ & 2.5 & $1.4-4.6$ & 0.003 \\
\hline $\begin{array}{l}\text { Time-to-metastasis ( } \geqslant \text { vs } 5 \text { years } \\
\text { from diagnosis) }\end{array}$ & 0.5 & $0.2-1.0$ & 0.026 \\
\hline Visceral metastatic disease & 1.7 & $1.0-3.1$ & 0.056 \\
\hline \multicolumn{4}{|l|}{ Molecular subgroup } \\
\hline $\begin{array}{l}\text { Luminal A } \\
\text { Luminal B-HER2-negative } \\
\text { Luminal B-HER2-positive } \\
\text { HER2-positive (non-luminal) } \\
\text { Triple negative }\end{array}$ & $\begin{array}{l}1 \\
1.8 \\
0.8 \\
0.1 \\
2.0\end{array}$ & $\begin{array}{c}- \\
0.8-4.0 \\
0.4-1.7 \\
0.02-1.1 \\
0.9-4.3\end{array}$ & $\begin{array}{l}- \\
0.146 \\
0.592 \\
0.057 \\
0.097\end{array}$ \\
\hline $\begin{array}{l}\text { Abbreviations: } \mathrm{Cl}=\text { confidence interv } \\
\text { survival. Bold values indicate significant }\end{array}$ & $\begin{array}{l}=c \\
\mathrm{~s}(P\end{array}$ & tumour & OS $=$ overal \\
\hline
\end{tabular}

and OS. In addition, with respect to PFS the presence of metastatic disease limited to the bone was significantly associated with longer PFS, whereas a statistical trend for shorter PFS was observed in patients with TN breast cancer. For OS, additional associations with decreased survival were observed for older age, metastatic relapse within 5 years from diagnosis of the primary breast tumour, the presence of visceral metastatic disease (trend) and TN tumour phenotype (trend). A statistical trend for better OS was furthermore observed for patients with non-luminal HER2-positive breast cancer (Table 3 ).

CTC evolution over the course of treatment. For almost half of the patients (75 of 154), CTC results from a second sample after the initiation of treatment were available. The average interval between baseline and FU CTC counts was 6 weeks (95\% CI, 5-8 weeks). An early decline from $\geqslant 5$ CTCs at the start of treatment to $<5$ CTCs after 1-2 months of treatment was associated with a shift towards a better PFS and OS in the total study population (Figure 4). All but 1 out of 19 HER2-positive patients who had $\geqslant 5$ CTCs before the start of treatment converted to counts $<5$ after the initiation of treatment, including anti-HER2-directed agents. The poorest CTC conversion rate (5 out of 17 patients) was observed in patients with Luminal A tumours (Table 4). Of the 12 patients in this subgroup, who did not show an early CTC conversion under treatment, 9 received hormonal treatment and 3 received chemotherapy alone.

\section{DISCUSSION}

With the introduction of the FDA-cleared CellSearch system early in 2004, the enumeration of CTCs has evolved to an established prognostic factor in patients with MBC. In this study, we explored potential differences in CTC detection and their prognostic significance in clinically relevant subgroups of patients with MBC. Similar subgroup analyses have been performed in three studies, including patients with MBC across different lines of systemic treatment for metastatic disease (Giordano et al, 2012; Munzone et al, 2012; Wallwiener et al, 2012). Results of these studies are summarised in Table 5. Several studies have however suggested that different treatment modalities and particularly targeted treatments can exhibit profoundly different effects on CTC counts and biology (Bidard et al, 2010; Giuliano et al, 2011; Pierga et al, 2012), which might affect the 'natural' distribution and characteristics of CTC beyond first-line treatment. Therefore, in this study we have chosen to exclusively include 154 patients with MBC who were previously untreated for metastatic disease from our institutional database.

In contrast to the previous studies in which higher percentages of $\geqslant 5$ CTCs per $7.5 \mathrm{ml}$ were reported in patients with hormone receptor positive/Luminal breast cancer (Table 5), we observed no statistically significant differences in the absolute CTC counts or CTC positivity rates at a detection limit of $\geqslant 1$ CTC per $7.5 \mathrm{ml}$ blood or the $\geqslant 5$ CTCs per $7.5 \mathrm{ml}$ prognostic cut-off point between the different immunohistochemical subgroups. This observation is in agreement with other studies reporting on CTC enumeration in patients with $\mathrm{MBC}$ before first-line treatment (Giuliano et al, 2011; Pierga et al, 2012).

Given the differences in biology and the previously described differences in EpCAM expression observed in primary breast tumours and cell line models between the intrinsic subtypes of breast cancer (Sieuwerts et al, 2009; Van Laere et al, 2009; Soysal et al, 2013), the absence of any obvious association between the detection rate of EpCAM-positive CTC and any of the immunohistochemical subtypes observed in our study and other studies in patients with MBC before first-line treatment (Giuliano et al, 2011; Pierga et al, 2012), is at least remarkable. However, very high CTC counts - defined here as $\geqslant 80$ CTCs per $7.5 \mathrm{ml}$ blood - were observed significantly more frequently in patients with Luminal A 

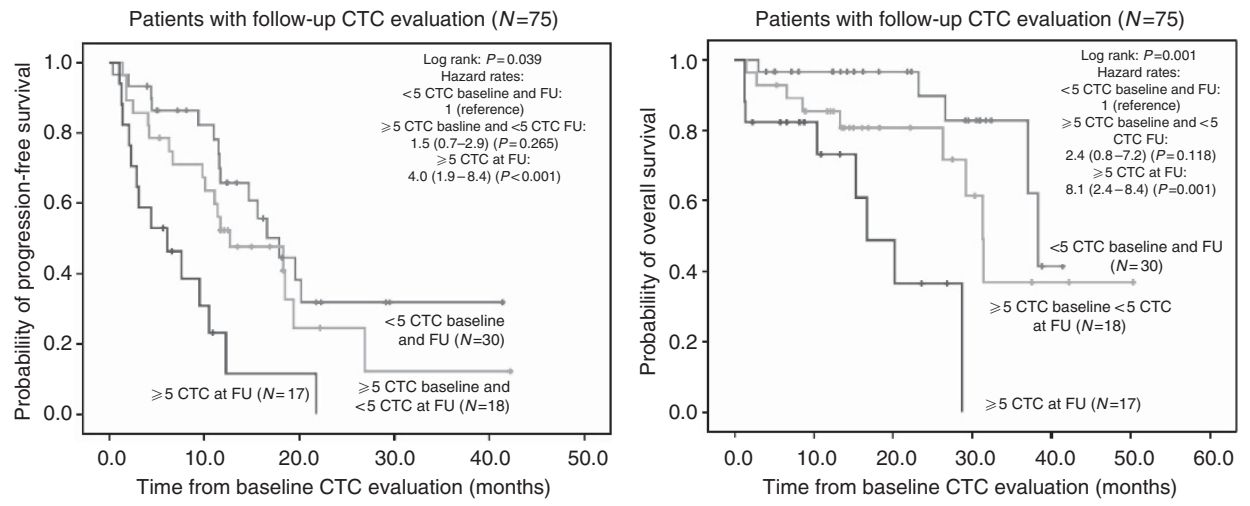

Figure 4. Kaplan-Meier curves of PFS and OS for 75 patients who had undergone follow-up CTC evaluation under treatment 1-2 months after baseline CTC evaluation.

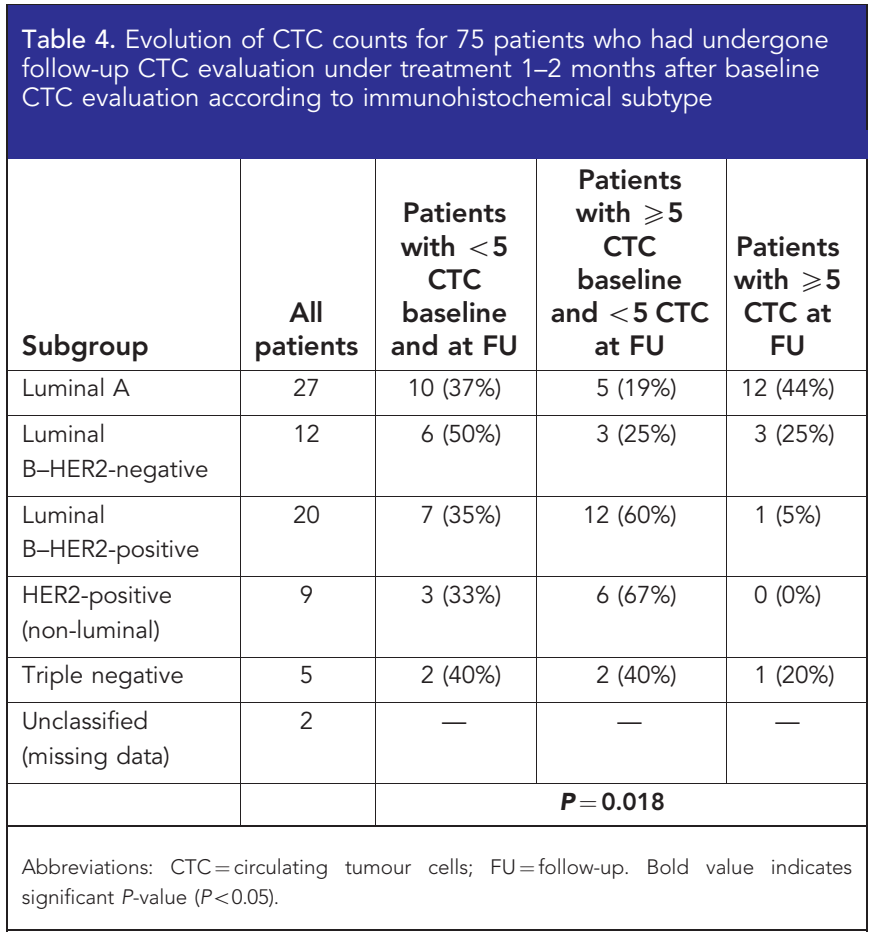

and TN breast cancer. Although the prognostic significance of CTC enumeration has been studied mostly relative to the $\geqslant 5$ CTCs cutoff point as determined in the seminal paper by Cristofanilli et al (2004), several research groups have shown that even beyond this cut-off point increasing risks of both progression and death can be observed with increasing numbers of CTCs (Botteri et al, 2010; Giordano et al, 2011). This idea of using CTC count as a continuous variable has recently been further conceptualised with the development of prognostic nomograms that could predict clinical outcome in patients with $\mathrm{MBC}$ starting first-line treatment as a function of baseline CTC counts (among other prognostic parameters) based on the pooled data of a large population of 446 patients (Giordano et al, 2013). In this study, the authors were able to show that continuous CTC counts up to 80 CTCs per $7.5 \mathrm{ml}$ blood could lead to a significantly more powerful prediction of OS than a dichotomised CTC count. Moreover, in our patient population, the presence of $\geqslant 80$ CTCs per $7.5 \mathrm{ml}$ blood was associated with a further worsening in clinical outcome when compared with the classical $\geqslant 5$ CTCs per $7.5 \mathrm{ml}$ cut-off point (Supplementary Figure 2 and Supplementary Table 1), suggesting that patients with extremely high CTC counts might represent a subset of patients with particularly aggressive tumour biology.
Our study furthermore confirms the presence of $\geqslant 5$ CTC per $7.5 \mathrm{ml}$ as the single most significant prognostic factor for both PFS and $\mathrm{OS}$ in patients with $\mathrm{MBC}$ before the start of first-line treatment, irrespective of classical prognostic factors such as site and extent of metastatic disease and serological markers. Although the presence of $\geqslant 5$ CTCs was associated with decreased median survival times in all immunohistochemically defined subgroups, a more limited, not statistically significant prognostic value of CTC enumeration was observed in patients with HER2-positive breast cancers. Therefore, our data independently confirm those reported by Giordano et al (2012) both with regard to PFS and OS in a large and clinically more uniform population of patients with MBC before first-line treatment. Similar results with respect to PFS have also been reported by Munzone et al (2012) and Wallwiener et al (2012). However, when evaluating OS, in the study of Munzone et al (2012), the presence of $\geqslant 5$ CTCs maintained its predictive value for poorer outcome in all breast cancer subtypes. In the study of Wallwiener et al (2012), a decreased prognostic significance of having $\geqslant 5$ CTCs before the start of a new line of treatment was observed only in HER2-positive patients who had already been pretreated with trastuzumab.

An impressive observation in this study is the remarkably good prognosis with respect to OS in the patients with HER2-positive MBC and particularly in those patients with nonluminal HER2-positive disease. This observation is in keeping with the exceptional disease control rates that are currently standard of care for patients suffering from HER2-amplified $\mathrm{MBC}$ and reflects the high efficacy of targeted treatment options that are now available for these patients (Swain et al, 2013). Further in line with these findings and the results from previous studies (Giuliano et al, 2011; Pierga et al, 2012), CTCs were found to be cleared more efficiently from the bloodstream over the course of treatment in HER2-positive patients treated with HER2-targeting agents than in patients with Luminal/HER2-negative and TN breast cancers. The excellent clinical outcome combined with this rapid clearance of CTCs in nearly all of our patients in this subgroup most probably explains the lesser degree of prognostic significance in this group.

Equally impressive as the excellent clinical outcome observed in HER2-positive patients in this study is the poor prognosis observed in patients with TN disease. This particularly holds true for the patients with unfavourable CTC counts. Interestingly, four of the five patients within this subgroup having $\geqslant 80$ CTCs per $7.5 \mathrm{ml}$ blood died within 1 year from diagnosis of metastatic disease. Although these data have to be interpreted cautiously given the limited number of patients in this analysis, this further underscores the need for accurate identification and better characterisation of patients with extremely high CTC counts, as these might be in most urgent need for more aggressive treatment. 
Table 5. Overview of published studies that have specifically addressed potential differences in CTC detection and prognostic significance between immunohistochemically defined subtypes of breast cancer

\begin{tabular}{|c|c|c|c|c|c|}
\hline \multirow[b]{2}{*}{ Reference } & \multirow[b]{2}{*}{$\begin{array}{l}\text { Patient } \\
\text { population }\end{array}$} & \multirow[b]{2}{*}{$\begin{array}{l}\text { Subtype classification and } \\
\text { distribution }\end{array}$} & \multirow[b]{2}{*}{$\begin{array}{l}\text { Association subtypes- } \\
\text { CTC counts/positivity } \\
\text { rates }\end{array}$} & \multicolumn{2}{|c|}{$\begin{array}{c}\text { Association subtypes-CTC prognostic } \\
\text { significance }\end{array}$} \\
\hline & & & & PFS & OS \\
\hline $\begin{array}{l}\text { Giordano } \\
\text { et al, } 2012\end{array}$ & $\begin{array}{c}N=517 \\
(45.8 \% \text { first-line) }\end{array}$ & $\begin{array}{l}\text { HR-positive/HER2-negative } \\
\text { (56.4\%) } \\
\text { HR-positive/HER2-positive (9.7\%) } \\
\text { HR-negative/HER2-positive (9.9+) } \\
\text { TN (24.0\%) }\end{array}$ & $\begin{array}{l}\geqslant 5 \text { CTC associated with } \\
\text { HR-positive/HER2-negative } \\
\text { subtype }\end{array}$ & $\begin{array}{l}\geqslant 5 \text { CTC significantly only } \\
\text { associated with shorter } \\
\text { PFS in HR-positive/ } \\
\text { HER2-negative subtype }\end{array}$ & $\begin{array}{l}\geqslant 5 \text { CTC significantly } \\
\text { associated with shorter OS } \\
\text { only in HR-positive/ } \\
\text { HER2-negative and TN } \\
\text { subtypes; trend in HR- } \\
\text { positive/HER2-positive } \\
\text { subtype; no association in } \\
\text { HR-negative/HER2- } \\
\text { positive subtype }\end{array}$ \\
\hline $\begin{array}{l}\text { Munzone } \\
\text { et al, } 2012\end{array}$ & $\begin{array}{c}N=203 \\
(26.1 \% \text { first-line })\end{array}$ & $\begin{array}{l}\text { Goldhirsch et al, } 2011 \\
\text { (ER, PR, HER2, grade, Ki67): } \\
\text { Lum A (13.3\%) } \\
\text { Lum B-HER2-negative (51.7\%) } \\
\text { Lum B-HER2-positive (14.3\%) } \\
\text { HER2-positive (11.8\%) } \\
\text { Basal-like (8.9\%) }\end{array}$ & $\begin{array}{l}\text { CTC more often found in } \\
\text { Lum A and Lum } \\
\text { B-HER2-negative subtype }\end{array}$ & $\begin{array}{l}\geqslant 5 \text { CTC significantly } \\
\text { associated with shorter } \\
\text { PFS in lumimal-HER2- } \\
\text { negative subtypes but not } \\
\text { in HER2-positive and TN } \\
\text { subtypes }\end{array}$ & $\begin{array}{l}\geqslant 5 \text { CTC significantly } \\
\text { associated with shorter OS } \\
\text { in all subtypes }\end{array}$ \\
\hline $\begin{array}{l}\text { Wallwiener } \\
\text { et al, } 2012\end{array}$ & $\begin{array}{c}N=486 \\
(37.7 \% \text { first-line })\end{array}$ & $\begin{array}{l}\text { HR-positive/HER2-negative (52\%) } \\
\text { HER2-positive (24\%) } \\
\text { HR-negative/HER2-negative (18\%) }\end{array}$ & $\begin{array}{l}\geqslant 5 \text { CTC associated with } \\
\text { ER-positive status }\end{array}$ & $\begin{array}{l}\geqslant 5 \text { CTC significantly } \\
\text { associated with shorter } \\
\text { PFS in HR-positive/HER2- } \\
\text { negative and HR-negative/ } \\
\text { HER2-negative subtypes } \\
\text { but not in HER2-positive } \\
\text { subtype }\end{array}$ & $\begin{array}{l}\geqslant 5 \text { CTC significantly } \\
\text { associated with shorter OS } \\
\text { in all subtypes except for } \\
\text { HER2-positive patients } \\
\text { that had been pretreated } \\
\text { with trastuzumab }\end{array}$ \\
\hline
\end{tabular}

Finally, in this study a strong association was observed between lobular primary tumour histology and the occurrence of higher CTC counts at the time of metastatic disease. In line with the typical pathological characteristics of lobular carcinomas (Arpino et al, 2004), most patients with lobular carcinoma in our study population (19 out of $25(76 \%))$ exhibited Luminal A primary tumour characteristics, representing $34 \%$ of all patients in the Luminal A subgroup. Therefore, the stronger association of high CTC counts in patients with lobular carcinoma is likely to account at least in part for the slightly increased incidence of high CTC counts in patients in the Luminal A subgroup. Indeed, when classified according to CTC counts, 16 out of 29 (62\%) Luminal A patients with $\geqslant 5$ CTCs and 7 out of $11(64 \%)$ with $\geqslant 80$ CTCs had lobular primary tumour histology. Higher detection rates of disseminated tumour cells in the bone marrow and (EpCAM + ) CTCs in the bloodstream have already been reported in patients with stage I-III breast cancer (Vincent-Salomon et al, 2009; Gainer et al, 2012). Interestingly, however, when evaluating EpCAM expression immunohistochemically in 1365 primary breast tumour, Soysal et al (2013) reported a lower EpCAM positivity in only $26 \%$ of patients with lobular carcinoma as compared with $51 \%$ in patients with ductal carcinoma. Lobular carcinomas comprise $\sim 10 \%$ of breast cancers and are characterised histologically by the presence of small, non-cohesive cancer cells attributed to the loss of E-cadherin, which might explain a higher tendency for invasion of these cells in the bloodstream (Arpino et al, 2004). This is furthermore supported by the clinical observation that lobular carcinomas are more frequently associated with diffuse and unusual dissemination patterns, including metastatic disease to the gastrointestinal tract and the ovaries.

In this study, surrogate definitions for the classification of breast cancer subtypes using crude pathological criteria have been used.
Although these definitions closely reflect therapeutically relevant subgroups of breast cancer distinguished in every day's clinical practice, our results could not be used to draw any conclusion with respect to potential differences in the detection or prognostic significance of EpCAM-positive CTCs in intrinsic subtypes of breast cancer as defined by global gene-expression profiling. Other major limitations of this study are the retrospective, exploratory nature of the analysis and - as accounts for most previously published studies - the relatively small patient population to conduct adequately powered subgroup analyses. Although overall good concordances were observed with other studies, results from this study have therefore to be regarded as hypothesis generating and should be further tested in larger patient populations. From this perspective, it will be of interest to see the results of the large pooled analysis of European CTC data in patients with MBC, which is currently ongoing. In addition, several prospective interventional trials evaluating the potential beneficial effect on clinical outcome of CTC-driven treatment approaches as compared with traditional radiographic and clinical monitoring of treatment effect in patients with MBC have now been initiated (Bidard et al, 2013). Results of these trials will have to be awaited in order to be able to determine whether CTC enumeration and monitoring could ultimately fulfil their promising role as a surrogate marker for treatment efficacy c.q. resistance in the management of patients with MBC.

\section{ACKNOWLEDGEMENTS}

We sincerely thank all patients who gave blood samples for research intentions. We acknowledge all research nurses of the 
Clinical Trial Organisation and lab technicians of the Translational Cancer Research Unit of GZA Hospitals Sint-Augustinus, Antwerp, Belgium, for their assistance in collecting and analysing blood samples. DJEP is a research assistant of the Fund for Scientific Research Flanders. This project was partially financed by grants of the Belgian 'Stichting tegen Kanker'.

\section{REFERENCES}

Arpino G, Bardou VJ, Clark GM, Elledge RM (2004) Infiltrating lobular carcinoma of the breast: tumor characteristics and clinical outcome. Breast Cancer Res 6: R149-R156.

Bidard F-C, Fehm T, Ignatiadis M, Smerage JB, Alix-Panabières C, Janni W, Messina C, Paoletti C, Müller V, Hayes DF, Piccart M, Pierga J-Y (2013) Clinical application of circulating tumor cells in breast cancer: overview of the current interventional trials. Cancer Metastasis Rev 32: 179-188.

Bidard F-C, Mathiot C, Degeorges A, Etienne-Grimaldi M-C, Delva R, Pivot X, Veyret C, Bergougnoux L, De Cremoux P, Milano G, Pierga J-Y (2010) Clinical value of circulating endothelial cells and circulating tumor cells in metastatic breast cancer patients treated first line with bevacizumab and chemotherapy. Ann Oncol 21: 1765-1771.

Botteri E, Sandri MT, Bagnardi V, Munzone E, Zorzino L, Rotmensz N, Casadio C, Cassatella MC, Esposito A, Curigliano G, Salvatici M, Verri E, Adamoli L, Goldhirsch A, Nolè F (2010) Modeling the relationship between circulating tumour cells number and prognosis of metastatic breast cancer. Breast Cancer Res Treat 122: 211-217.

Cristofanilli M, Budd GT, Ellis MJ, Stopeck A, Matera J, Miller MC, Reuben JM, Doyle GV, Allard WJ, Terstappen L.W.M.M., Hayes DF (2004) Circulating tumor cells, disease progression, and survival in metastatic breast cancer. N Engl J Med 351: 781-791.

Gainer SM, Lodhi AK, Bhattacharyya A, Krishnamurthy S, Kuerer HM, Lucci A (2012) Invasive lobular carcinoma predicts micrometastasis in breast cancer. J Surg Res 177: 93-96.

Giordano A, Egleston BL, Hajage D, Bland J, Hortobagyi GN, Reuben JM, Pierga J-Y, Cristofanilli M, Bidard F-C (2013) Establishment and validation of circulating tumor cell-based prognostic nomograms in firstline metastatic breast cancer patients. Clin Cancer Res 19: 1596-1602.

Giordano A, Giuliano M, De Laurentiis M, Arpino G, Jackson S, Handy BC, Ueno NT, Andreopoulou E, Alvarez RH, Valero V, De Placido S, Hortobagyi GN, Reuben JM, Cristofanilli M (2012) Circulating tumor cells in immunohistochemical subtypes of metastatic breast cancer: lack of prediction in HER2-positive disease treated with targeted therapy. Ann Oncol 23: 1144-1150.

Giordano A, Giuliano M, Laurentiis M, Eleuteri A, Iorio F, Tagliaferri R, Hortobagyi GN, Pusztai L, Placido S, Hess K, Cristofanilli M, Reuben JM (2011) Artificial neural network analysis of circulating tumor cells in metastatic breast cancer patients. Breast Cancer Res Treat 129: 451-458.

Giuliano M, Giordano A, Jackson S, Hess KR, De Giorgi U, Mego M, Handy BC, Ueno NT, Alvarez RH, De Laurentiis M, De Placido S, Valero V, Hortobagyi GN, Reuben JM, Cristofanilli M (2011) Circulating tumor cells as prognostic and predictive markers in metastatic breast cancer patients receiving first-line systemic treatment. Breast Cancer Res 13: R67.

Goldhirsch A, Wood WC, Coates AS, Gelber RD, Thürlimann B, Senn H-J. Panel members (2011) Strategies for subtypes-dealing with the diversity of breast cancer: highlights of the St Gallen International Expert Consensus on the Primary Therapy of Early Breast Cancer 2011. Ann Oncol 22: 1736-1747.

Kahan LS (2004) Medical devices; immunology and microbiology devices; classification of the immunomagnetic circulating cancer cell selection and enumeration system. Final rule. (Federal Register).

McShane LM, Altman DG, Sauerbrei W, Taube SE, Gion M, Clark GM. Statistics Subcommittee of the NCI-EORTC Working Group on Cancer Diagnostics (2005) Reporting recommendations for tumor marker prognostic studies. J Clin Oncol 23: 9067-9072.

Munzone E, Botteri E, Sandri MT, Esposito A, Adamoli L, Zorzino L, Sciandivasci A, Cassatella MC, Rotmensz N, Aurilio G, Curigliano G, Goldhirsch A, Nolè F (2012) Prognostic value of circulating tumor cells according to immunohistochemically defined molecular subtypes in advanced breast cancer. Clin Breast Cancer 12: 340-346.
Perou CM, Sørlie T, Eisen MB, van de Rijn M, Jeffrey SS, Rees CA, Pollack JR, Ross DT, Johnsen H, Akslen LA, Fluge O, Pergamenschikov A, Williams C, Zhu SX, Lønning PE, Børresen-Dale AL, Brown PO, Botstein D (2000) Molecular portraits of human breast tumours. Nature 406: 747-752.

Pierga J-Y, Hajage D, Bachelot T, Delaloge S, Brain E, Campone M, Dieras V, Rolland E, Mignot L, Mathiot C, Bidard F-C (2012) High independent prognostic and predictive value of circulating tumor cells compared with serum tumor markers in a large prospective trial in first-line chemotherapy for metastatic breast cancer patients. Ann Oncol 23: 618-624.

Schemper M, Smith TL (1996) A note on quantifying follow-up in studies of failure time. Control Clin Trials 17: 343-346.

Sieuwerts AM, Kraan J, Bolt J, van der Spoel P, Elstrodt F, Schutte M, Martens JWM, Gratama J-W, Sleijfer S, Foekens JA (2009) Anti-epithelial cell adhesion molecule antibodies and the detection of circulating normal-like breast tumor cells. J Natl Cancer Inst 101: 61-66.

Sorlie T, Tibshirani R, Parker J, Hastie T, Marron JS, Nobel A, Deng S, Johnsen H, Pesich R, Geisler S, Demeter J, Perou CM, Lønning PE, Brown PO, Børresen-Dale A-L, Botstein D (2003) Repeated observation of breast tumor subtypes in independent gene expression data sets. Proc Natl Acad Sci USA 100: 8418-8423.

Sotiriou C, Neo S-Y, McShane LM, Korn EL, Long PM, Jazaeri A, Martiat P, Fox SB, Harris AL, Liu ET (2003) Breast cancer classification and prognosis based on gene expression profiles from a population-based study. Proc Natl Acad Sci USA 100: 10393-10398.

Soysal SD, Muenst S, Barbie T, Fleming T, Gao F, Spizzo G, Oertli D, Viehl CT, Obermann EC, Gillanders WE (2013) EpCAM expression varies significantly and is differentially associated with prognosis in the luminal B HER2 ${ }^{+}$, basal-like, and HER2 intrinsic subtypes of breast cancer. Br J Cancer 108: 1480-1487.

Swain SM, Kim S-B, Cortes J, Ro J, Semiglazov V, Campone M, Ciruelos E, Ferrero J-M, Schneeweiss A, Knott A, Clark E, Ross G, Benyunes MC, Baselga J (2013) Pertuzumab, trastuzumab, and docetaxel for HER2positive metastatic breast cancer (CLEOPATRA study): overall survival results from a randomised, double-blind, placebo-controlled, phase 3 study. Lancet Oncol 14: 461-471.

The Cancer Genome Atlas Network (2012) Comprehensive molecular portraits of human breast tumours. Nature 490: 61-70.

Van Der Auwera I, Peeters D, Benoy IH, Elst HJ, Van Laere SJ, Prové A, Maes H, Huget P, van Dam P, Vermeulen PB, Dirix LY (2010) Circulating tumour cell detection: a direct comparison between the CellSearch System, the AdnaTest and CK-19/mammaglobin RT-PCR in patients with metastatic breast cancer. Br J Cancer 102: 276-284.

Van Laere S, Van Der Auwera I, Van den Eynden G, Van Hummelen P, van Dam P, Van Marck E, Vermeulen PB, Dirix L (2007) Distinct molecular phenotype of inflammatory breast cancer compared to non-inflammatory breast cancer using Affymetrix-based genome-wide gene-expression analysis. Br J Cancer 97: 1165-1174.

Van Laere SJ, Elst H, Peeters D, Benoy I, Vermeulen PB, Dirix LY (2009) Re: Anti-epithelial cell adhesion molecule antibodies and the detection of circulating normal-like breast tumor cells. J Natl Cancer Inst 101: 895-896.

Vincent-Salomon A, Caly M, De Rycke Y, Fréneaux P, Klijanienko J, Laé M, Viard F, Nos C, Bidard F-C, Alran S, Salmon R, Kirova Y, Pierga J-Y, Sigal-Zafrani B, Sastre-Garau X (2009) Lobular phenotype related to occult-metastatic spread in axillary sentinel node and/or bone marrow in breast carcinoma. Eur J Cancer 45: 1979-1986.

Wallwiener M, Hartkopf AD, Baccelli I, Riethdorf S, Schott S, Pantel K, Marmé F, Sohn C, Trumpp A, Rack B, Aktas B, Solomayer E-F, Müller V, Janni W, Schneeweiss A, Fehm TN (2012) The prognostic impact of circulating tumor cells in subtypes of metastatic breast cancer. Breast Cancer Res Treat 137: 503-510.

Zhang L, Riethdorf S, Wu G, Wang T, Yang K, Peng G, Liu J, Pantel K (2012) Meta-analysis of the prognostic value of circulating tumor cells in breast cancer. Clin Cancer Res 18: 5701-5710.

This work is published under the standard license to publish agreement. After 12 months the work will become freely available and the license terms will switch to a Creative Commons AttributionNonCommercial-Share Alike 3.0 Unported License. 